\title{
Ionizing Radiation-inducible microRNA-21 Induces Angiogenesis by Directly Targeting PTEN
}

\author{
Yongchun Zhang*, Zhiying Chen, Lingxin Feng, Peng Jiang, Xiumei Li, Xiang \\ Wang
}

\begin{abstract}
Background: Previous experimental studies have established that MicroRNAs (miRNAs) can function as oncogenes or tumor suppressors in the regulation of tumor biology or pathology. However, the effects of ionizing radiation (IR) on the expression levels of cellular miRNAs and their further effects on the biological behavior of tumor cells require further investigation. Methods: We determined the proliferation, migration and tube formation of HUVEC cells after ionizing radiation (control, $0 \mathrm{~h}$ and $24 \mathrm{~h}$ ), and the changes of $m i R-21$, VEFG and HIF- $1 \alpha$ levels after ionizing radiation were measured by Western blot (WB). The effects of $m i R-21$ mimics and inhibitors on the protein and mRNA expression of PTEN were determined by RT-PCT and WB. Two independent luciferase reporter plasmids were constructed to detect changes in PTEN protein expression. Results: We found that both IR and $m i R-21$ increase proliferation, migration and tube formation of HUVEC cells. Ionizing radiation directly targets the inhibition of PTEN expression by causing an increase in $m i R-21$ expression, and induces the accumulation of VEGF and HIF-1 $\alpha$ expression in cells by the PI3K/AKT signaling pathway. Simultaneous induction of ectopic expression of PTEN can rescue radiation-induced proliferation, migration and tube formation in tumor cells. Conclusion: $m i R-21$ promotes tumor cell proliferation and migration by targeting inhibition of PTEN expression, which may become a potential target for tumor therapy in the future.
\end{abstract}

Keywords: MicroRNA 21- angiogenesis- PTEN- ionization- HIF-1 $\alpha$

Asian Pac J Cancer Prev, 20 (5), 1587-1593

\section{Introduction}

Ionizing radiation, as a high-energy physics damaging factors, can produce free radicals by ionizing stimulation, resulting in the alteration of a number of ionizing radiation inducible genes (IRIG). The IRIG, such as GADD45, ATM, p53 (Artuso et al., 1995; Long et al., 2007; Dean et al., 2009), are widely involved in cell cycle regulation, DNA damage repair, cell growth regulation and apoptosis. Recent studies have found a new class of non-coding RNA, micro RNA (miRNA) are also involved in the process of radiation-induced biological response (Kwon et al., 2013; Zhao et al., 2014; Kwak et al., 2015). Recent studies revealed that radiation can induce a series of miRNA expression and there is a close relationship between miRNA and radiation sensitivity, and the radiation-induced tumorigenesis and bystander effects. Therefore, it is of great significance to investigate how miRNA is involved in the biological effects induced by ionizing radiation and these will reveal its molecular biological mechanisms and provide potential clinical value.

$m i R-21$ upregulation participated in various tumor progression, and is correlated with tumor metastasis (Bartel ,2004; Quintero et al., 2004; Griffiths-Jones et al., 2006; Suarez and Sessa, 2009), but the causes of $m i R-21$ upregulation and its direct role targeting tumor angiogenesis remains to be classified. Angiogenesis is essential for tumor growth and metastasis. The relavant marker, such as VEGF, plays a key role in regulating angiogenesis both in embryo and tumor (Melillo, 2004; Axelson et al., 2005), which is regulated by HIF-1 through transcriptional activation (Ghosh et al., 2009). In our study, we demonstrated of $m i R-21$ overexpression induced by ionization, which could increased HIF-1a and VEGF expression by PI3K/AKT/PTEN signaling pathway and induced tumor angiogenesis.

\section{Materials and Methods}

\section{Cell lines and culture conditions}

Huvec cell lines were obtained from the American Type Culture Collection (ATCC). The cell line was cultured in RPMI 1640 (Gibco) supplemented with $10 \%$ fetal bovine serum (FBS), and maintained at $37^{\circ} \mathrm{C}$ in $5 \% \mathrm{CO}_{2}$. The total RNA isolation was performed using miniBEST universal RNA extraction kit (Takara Bio, Inc.). The cellular protein isolation was performed and its concentration was detected by the BCA protein kit (Pierce, 
Rockford, IL.) for the WB assays.

\section{RNAi system and plasmid constructon}

specific siRNAs targeting microRNA hsa-mir-21 [miRBase: MI0000077] were bought from Genepharm. primers. The $m i R-21$ mimics sequences were: 5'-GGAUGGUACUUUCAUUGAATT-3'; miR-21 inhibitor sequences were 5 ' - C G GCUUCC C A A UA A C A GUAT T-3', a nd the s c r a m b e seque n e : 5'-UUCUCCGAACGUGUCACGUTT-3'. We also construct $P T E N$ ectopic expression plasmid using pcDNA 3.0 vector.

\section{Transfection assays with RNAi or plasmids}

The pcDNA 3.0 plasmid or $m i R-21$ mimics and inhibitor were transiently transfected with Huvec cells. Briefly, the cells were plated at a density of $1 * 10^{5}$ cells/well in a six-well plate. After $24 \mathrm{~h}$, the plasmids or RNAi were diluted in Opti-MEM and incubated for $20 \mathrm{~min}$ at room temperature. Mixed lipofectant and the above solutions, and added into the plate. Then the cells were incubated for $12 \mathrm{~h}$, rinsed and replenished with RPMI 1640 containing $10 \%$ FBS. After $48 \mathrm{~h}$, the cells were harvested and isolated the RNA and protein for RT-PCR and WB.

\section{Cell proliferation assay}

We used SRB method to perform the proliferation assay. Huvec were seeded in 96-well plates and cultured for $24 \mathrm{~h}$. The cells were transfected with plasmid or RNAi or using conditioned media cultured for 24,48 , $72 \mathrm{~h}$, respectively. Then, the cells were fixed with $10 \%$ $\mathrm{w} / \mathrm{v}$ of trichloroacetic acid $(100 \mu \mathrm{L})$ at $4^{\circ} \mathrm{C}$ for $1 \mathrm{~h}$, and washed with deionized water. Till air-dried, the samples were stained with $100 \mu \mathrm{L}$ of SRB solution (in $0.4 \% \mathrm{w} / \mathrm{v}$ in acetic acid) for $20 \mathrm{~min}$ at room temperature. The plates were then washed with acetic acid (1\%) and air dried. Tris-base $(10 \mathrm{mM}, 100 \mu \mathrm{L}, \mathrm{pH} 10)$ was added to each well for solubilization. Optical density (O.D) values were measured at $540 \mathrm{~nm}$ with a reference wavelength of 630 nm using microtiter plate reader (VERSMax).

\section{RNA isolation and RT-qPCR analysis}

Total RNA was isolated by using miniBEST universal RNA extraction kit (Takara Bio, Inc.). Reverse transcription use RT-qPCR kits (Takara Bio, Inc.) or miRcute miRNA cDNA kit (TianGen Biotech,Beijing) were used to evaluate expression of PTEN and miR-21. GAPDH and U6 expression was used to normalize for variance. The PCR Primers pairs used for each genes were: miR-21 forward: CGCGGTAGCTTATCAGACTGATG, reverse: CAGTGCAGGGTCCGAGGTG; PTEN forward: CGACGGGAAGACAAGTTCAT, reverse: AGGTTTCCTCTGGTCCTGGT.

\section{WB assays}

Cells were lysed in RIPA lysis buffer at ice . An equal amount of protein $(20 \mu \mathrm{g})$ was subjected and fractionated using SDS-PAGE and transferred onto a polyvinylidene fluoride membrane (PVDF). Blocking the PVDF membranes in $3 \%$ bovine serum albumin in TBST buffer containing $0.1 \%$ Tween-20 for $1 \mathrm{~h}$ at roomm temperature and incubating with the indicated primary antibodies at $4^{\circ} \mathrm{C}$ overnight. Appropriate secondary antibodies were incubated at room temperature for $1 \mathrm{~h}$ and detected using the enhanced chemiluminescence detection system. The data were adjusted against loading control using GAPDH. The primary antibodies were listed as followed: anti-HIF-1 $\alpha$ (BD Biosciences, Bedford, MA, USA); anti-PTEN, anti-PI3K, anti-p-PI3K, anti-AKT, anti-p-AKT, anti VEGF, anti-GAPDH (Cell Signaling Technology).

\section{Reporter plasmids and luciferase activity assays}

Cells were transiently transfected with pCMV-Luc-WT/MT reporter plasmids, which contain PTEN-3'-UTR regulatory region, according to the manufacturer's instructions as mentioned above. The PTEN--3'-UTR activity was normalized via co-transfection of empty vector. The luciferase activity in the cells was quantified using a dual luciferase assay system (Promega) 24 hours after transfection.

\section{Results}

Ionization induced Huvec proliferation, migration and tube formation

To investigate the role of ionization on HUVEC, we used conditioned media to perform the proliferation, migration and tube formation assays. Three media were used, control, $0 \mathrm{~h}$ and $24 \mathrm{~h}$ conditional media. We could see that after $24 \mathrm{~h}$ ionization, the cell proliferation increased compared to the control groups (Figure 1A). Similarly, Huvec migration ability enhanced. The migrated cell numbers were much more than the control groups (Figure 1B). Besides, the tube formation capability was much stronger. The number of formed tubes increased after ionizationfor $24 \mathrm{~h}$ (Figure 1C). Our group previously found that high-dose radioation could up-regulate HIF-1 $\alpha$ expression (Zhang et al., 2014). In this study, we also confirmed that $24 \mathrm{~h}$ radioation could up-regulate HIF- $1 \alpha$ and VEGF expression (Figure 1D). Additionally, the concentration of VEGF also increased (Figure 1E).

\section{miR-21 promoted Huvec proliferation, migration and} tube formation

Pervasive studies uncovered a series of differentially expressed microRNAs after cell irradiation, among which $m i R-21$ was detailed verified (Xu et al.,2014). Here, we saw that $24 \mathrm{~h}$ ionization up-regualted $m i R-21$ expression level (Figure 2A), which implied that miR-21 might work after radioation. We then transfected the cells with $m i R-21$ mimics and inhibitor to verify cell biological changes. We firstly confirmed the transfecttion efficiency. Figure 2B showed that $m i R-21$ mimics did increase its RNA expression, while inhibitor decreased its expression. Consistently, Huvecs with $m i R-21$ mimics possess a higher ability of proliferation (Figure 2C), migration (Figure 2D), and tube formation (Figure 2E), compared to the control groups. These phenotype changes might be due to PI3K/ AKT/PTEN signalling pathway (Figure 2F). 
(a)

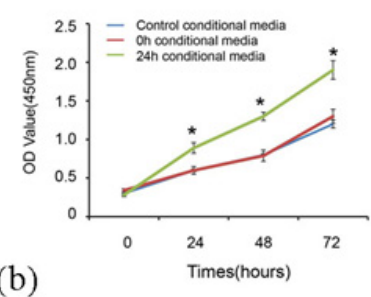

(b)
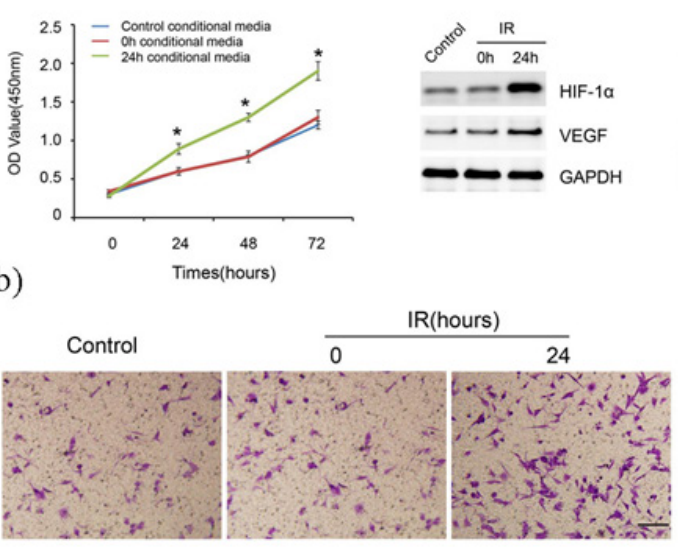

(e)
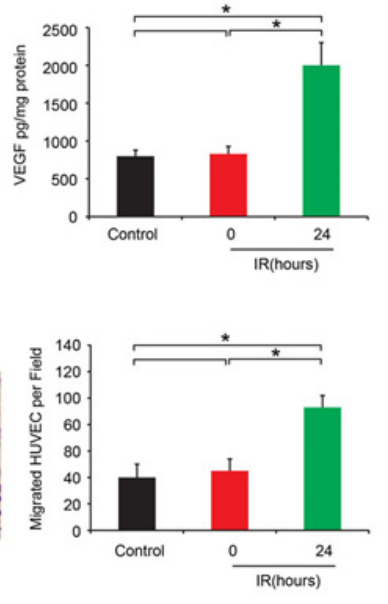

(c)

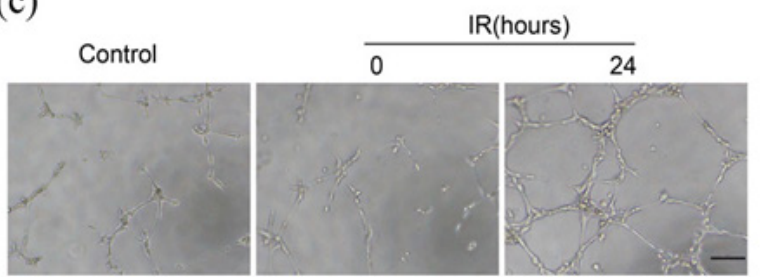

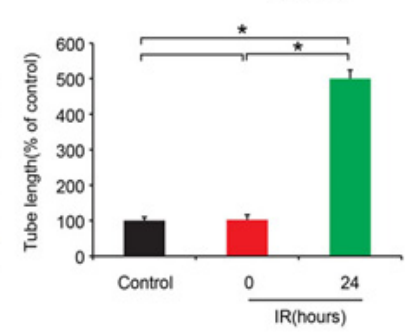

Figure 1. Ionization Induced Huvec Proliferation, Migration and Tube Formation. A.Huvec cells proliferation after $24 \mathrm{~h}$ ionization. B. Huvec migration ability after $24 \mathrm{~h}$ ionization. C. The tube formation capability after ionization. D. HIF- $1 \alpha$ and VEGF expression after $24 \mathrm{~h}$ ionization. E. The concentration of VEGF after $24 \mathrm{~h}$ ionization.

(a)

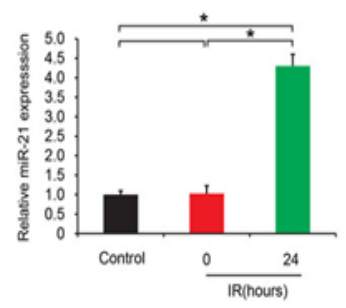

(d)

(e)
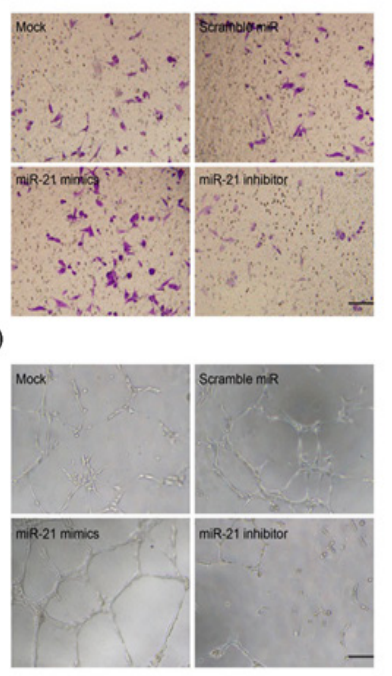

(b)

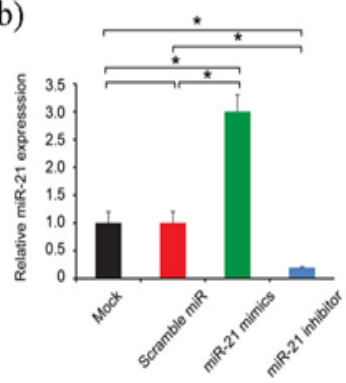

(c)

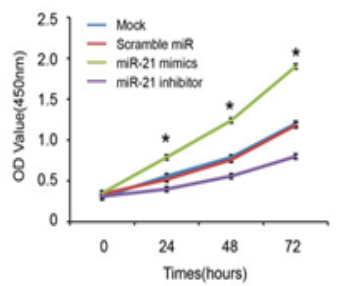

(f)
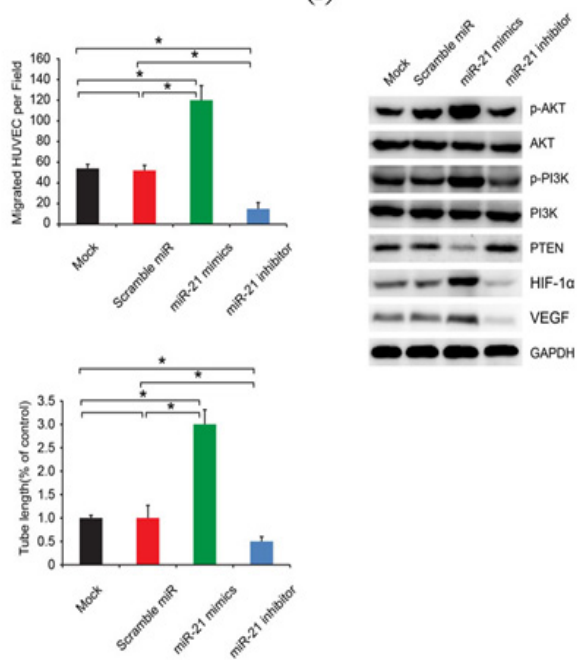

Figure 2. miR-21 Promoted Huvec Proliferation, Migration and Tube Formation. A. miR-21 expression level after 24h ionization. B. confirmation of miR-21 overexpression and knockdown. C. huvec cell proliferation after transfected with miR-21 mimics and inhibitor. D. huvec cell migration ability after transfected with miR-21 mimics and inhibitor. E. Tube formation ability after transfected with miR-21 mimics and inhibitor. F. PI3K/AKT/PTEN signalling pathway relative protein expression after transfected with miR-21 mimics and inhibitor. 
(a)

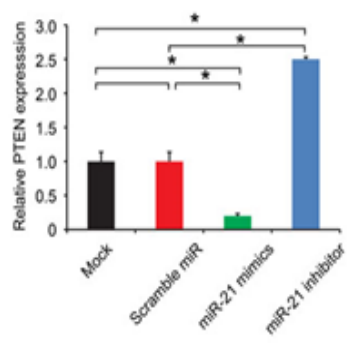

(b)

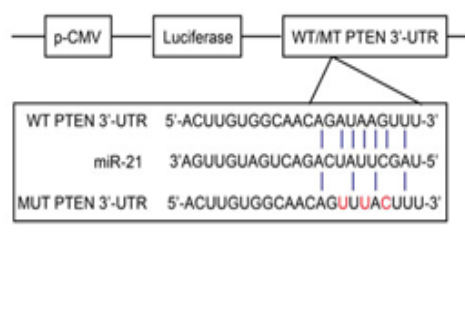

(c)

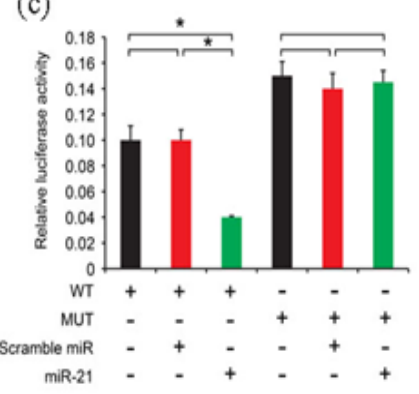

Figure 3. miR-21 Directly Targeted PTEN. A. PTEN mRNA level after transfected with miR-21 mimics and inhibitor B. two independent luciferase reporter plasmids were generated, containing cloned microRNA response elements (MREs) to miR-21 from the PTEN 3'-UTR regulatory region and its mutant type. C. luciferase activity in cells were transiently transfected with constructed plasmid with or without miR-21.

\section{miR-21 directly targeted PTEN}

microRNA usually act as tumor suppressor silencing in tumor progression (Farazi et al., 2013). Former WB experiment confirm that $m i R-21$ mimics could downregulate $P T E N$ protein expression. We aim to detect whether $m i R-21$ could regulate PTEN mRNA level. $P T E N$ mRNA level was increased after transfected with $m i R-21$ mimics, while decreased with $m i R-21$ inhibitor (a)

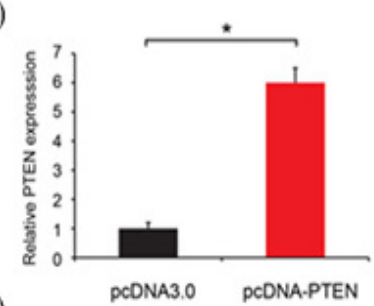

(c)

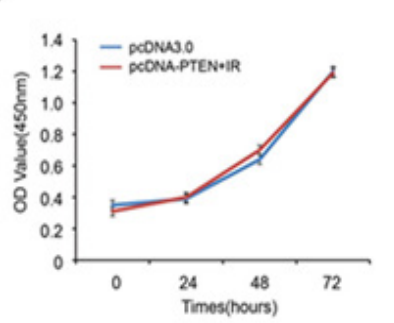

(b)

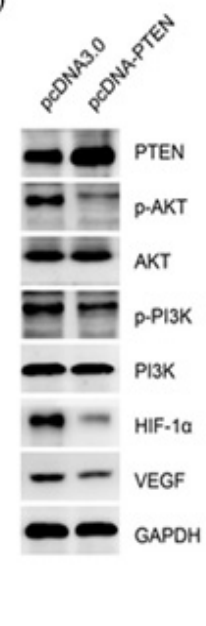

(f)

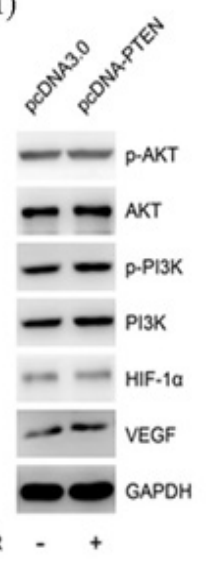

(d)
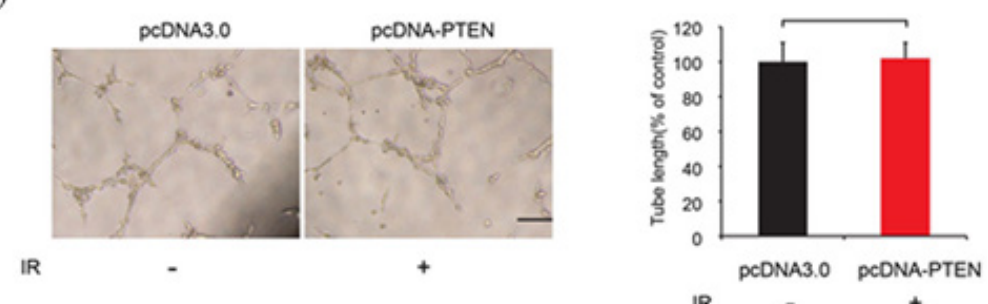

(e)

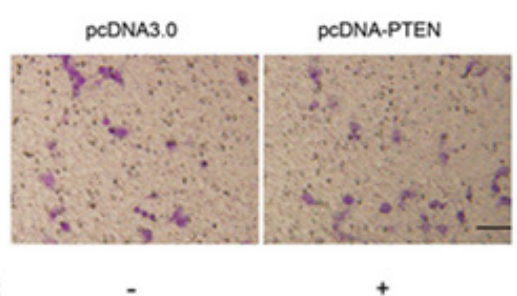

IR

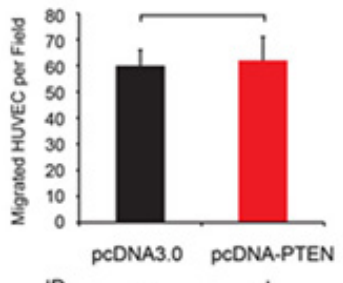

IR

Figure 4. PTEN Rescued Irradiation-induced Cell Proliferation, Migration and Tube Formation. A. The construction pcDNA-PTEN verification. B. PTEN, PI3K, AKT, HIF-1 $\alpha$ and VEGF protein level in two group, pcDNA3.0 (empty vector) and pcDNA-PTEN with irradiation. C. pcDNA-PTEN cell proliferation ability exposed to irradiation. D. pcDNA-PTEN cell migration ability exposed to irradiation. E. The pcDNA-PTEN cell tube formation bility exposed to irradiation. F. PTEN, PI3K, AKT, HIF-1 $\alpha$ and VEGF protein level in two group, pcDNA3.0 (empty vector) and pcDNA-PTEN with irradiation. 
(Figure 3A). Two independent luciferase reporter plasmids, containing cloned microRNA response elements (MREs) to $m i R-21$ from the PTEN 3'-UTR regulatory region and its mutant type, were constructed to demonstrate the direct target genet (Figure 3B). The cells were transfected with constructed plasmid, and found that transfection with pCMV-Luc-WT PTEN 3' UTR caused an obvious decrease in luciferase activity compared with empty vector group. However, the activity made no difference when transfected with mutant type plasmid (Figure 3C).

\section{PTEN rescued irradiation-induced cell proliferation, migration and tube formation}

Since irradiation could increase $m i R-21$ expression, which thereafter silenced $P T E N$ expression, we constructed stably transfected PTEN cell lines in order to verify whether PTEN could rescue the cell phenotype changes. The construction verification was shown in Figure 4A and B. PTEN mRNA and protein level both increased. We set our experiment in two group, pcDNA3.0 (empty vector) and pcDNA-PTEN with irradiation. Intriguingly, even if exposure to irradiation, the phenotypes of pcDNA-PTEN cells did not change, such as proliferation (Figure 4C), migration (Figure 4D) and tube formation (Figure 4E). WB analysis showed that ectopic expression of PTEN down-regulated PI3K, AKT, HIF-1 $\alpha$ and VEGF expression (Figure 4B), however, this phenomenon disappeared when the pcDNA-PTEN cells exposed to irradiation (Figure 4 F).

\section{Discussion}

Abnormally expressed miRNAs are detected in many cancer types and play critical roles in tumor biology, such as cell apoptosis and metastasis (Lu et al., 2005; Esquela-Kerscher and Slack, 2006; Hwang and Mendell, 2007; Landgraf et al., 2007). However, little is known about the functional role of miRNAs in participating the angiogenesis, which is a critical process in cancer development (Soucek et al., 2007), stimulating by hypoxia, cytokines, and growth factors (Semenza,2001, Goh et al., 2007; Liao and Johnson, 2007). Hypoxia inducible factor- $1 \alpha$ (HIF-1 $\alpha$ ) is a pivotal transcriptional factor regulates angiogenesis by inducing the VEGF expression, interleukin-8 (IL-8), and fibroblast growth factor (Seagroves et al., 2001). Pervious research implied that the synthesis of HIF-1 $\alpha$ is regulated through oxygen-independent mechanisms involving oncogene activation, such as H-Ras, myc, and src, tumor suppressor genes such as p53, PTEN, and VHL, and various growth factors (Kung et al., 2000; Vleugel et al., 2006; Zhou and Brune, 2006; Huang, 2008). $P T E N$ is a pivotal transcriptional factor for angiogenesis (He et al., 2016). We hypothesized that miRNAs might take part in PTEN regulation at the transcriptional level and that the dysregulation of miRNAs might contribute to the onset of angiogenesis. In this study, we identified $m i R-21$ as an IR-inducible miRNA that promotes angiogenesis directaly targeting PTEN via PI3K/AKT signaling pathway by increasing VEGF and HIF- $1 \alpha$ expression.
Ionized radiation could alter the microRNA profiles, such as let-7 family, $m i R-34, m i R-15, m i R-21, m i R-200 b$ (Simone et al., 2009, Marta et al., 2015). Thereinto, miR-21 was most highly regulated miRNA in both solid and haematological malignancies (Volinia et al., 2006), and it is associated with clinicopathological factors in various malignancies (Chan et al., 2008; Markou et al., 2008; Li et al., 2009; Gao et al., 2010; Hiroki et al., 2010; Motoyama et al., 2010). Pervious studies show that $m i R-21$ promotes proliferation, migration, invasion and cell cycle (Kuang and Nie, 2016; Li et al., 2016; Yan et al., 2016). In this study, we want to illustrate how miR-21 influence angiogenesis. We used HUVEC cells to verify our hypothesis. We used conditioned media (control, $0 \mathrm{~h}$ and $24 \mathrm{~h}$ ) to perform the proliferation, migration and tube formation assays. We could see that after $24 \mathrm{~h}$ ionization, the cell proliferation and migration ability increased compared to the control groups. Besides, the tube formation capability was much stronger. In this study, we also confirmed that $24 \mathrm{~h}$ radioation could up-regulate HIF- $1 \alpha$ and VEGF expression, which is vital for angiogenesis in cancer development. But the underlying mechanism remained to be cover. Among IRinduced genes, $m i R-21$ is essential for tumor development. We have showed that $m i R-21$ level was upregulated after ionized radiation. $m i R-21$ promoted Huvec proliferation, migration and tube formation. The downregulation or upregulation of many proteins or signaling pathway in the cell angiogenesis, such as CD64/PI3K/Akt (Chen et al.,2016), MAPK/ERK (Chen et al., 2016), Wnt/ $\beta$-catenin signaling pathway (Wang et al.,2016), were demonstrated. Here, we focus on an critical transcriptional factor PTEN participating in PI3K/Akt signaling pathway. We confirm that $m i R-21$ mimics could down-regulate PTEN protein and mRNA expression. Two independent luciferase reporter plasmids were constructed, and found that transfection with pCMV-Luc-WT PTEN 3' UTR caused an obvious decrease in luciferase activity compared with control group. However, transfected with mutant type plasmid did not make obvious difference. We could conclude that $m i R-21$ could directly target PTEN expression. We then carried out the rescue experiments. Interestingly, we showed that PTEN rescued irradiation-induced cell proliferation, migration and tube formation.

In our own study, we identified $m i R-21$ as a potent factor of IR-induced angiogenesis. IR induces $m i R-21$ expression, which in turn causes the downregulation of $P T E N$ and finally induces angiogenesis through increased VEGF and HIF- $1 \alpha$ through PI3K/AKT pathway.

In summary, we revealed a novel ionization dependent mechanism for regulating PTEN expression and inducing angiogenesis, which could be exploited to develop a novel anticancer strategy, especially for tumors that with low expression of PTEN. Dissecting the underlying mechanism of activity of $m i R-21$ in detail will help us understand how cell angiogenesis is regulated during ionized radiation, and is a focus of our future studies. 


\section{Acknowledgements}

This study was supported by the program from Shandong Provincial Education Department (J15LL09). Conceptualization, Y.C.Z.; Methodology, P.J.; Formal Analysis, L.X.F.; Investigation,X.W.; Writing - Original Draft Preparation, Z.Y.C; Writing - Review \& Editing, X.M.L.

\section{References}

Artuso M, Esteve A, Bresil H, Vuillaume M,Hall J (1995). The role of the Ataxia telangiectasia gene in the p53, WAF1/ CIP1(p21)- and GADD45-mediated response to DNA damage produced by ionising radiation. Oncogene, 11, 1427-35.

Axelson H, Fredlund E, Ovenberger M, Landberg G,Pahlman S (2005). Hypoxia-induced dedifferentiation of tumor cells-a mechanism behind heterogeneity and aggressiveness of solid tumors. Semin Cell Dev Biol, 16, 554-63.

Bartel DP (2004). MicroRNAs: genomics, biogenesis, mechanism, and function. Cell, 116, 281-97.

Chan SH, Wu CW, Li AF, Chi CW,Lin WC (2008). miR-21 microRNA expression in human gastric carcinomas and its clinical association. Anticancer Res, 28, 907-11.

Chen J, Gu Z, Wu M, et al (2016). C-reactive protein can upregulate VEGF expression to promote ADSC-induced angiogenesis by activating HIF-1alpha via CD64/PI3k/ Akt and MAPK/ERK signaling pathways. Stem Cell Res Ther, 7, 114.

Dean PJ, Siwiec T, Waterworth WM, et al (2009). A novel ATM-dependent X-ray-inducible gene is essential for both plant meiosis and gametogenesis. Plant $J, \mathbf{5 8}, 791-802$.

Esquela-Kerscher A, Slack FJ (2006). Oncomirs - microRNAs with a role in cancer. Nat Rev Cancer, 6, 259-69.

Farazi TA, Hoell JI, Morozov P, Tuschl T (2013). MicroRNAs in human cancer. Adv Exp Med Biol, 774, 1-20.

Gao W, Yu Y, Cao H, et al (2010). Deregulated expression of $m i R-21, m i R-143$ and $m i R-181$ a in non small cell lung cancer is related to clinicopathologic characteristics or patient prognosis. Biomed Pharmacother, 64, 399-408.

Ghosh AK, Shanafelt TD, Cimmino A, et al (2009). Aberrant regulation of $\mathrm{pVHL}$ levels by microRNA promotes the HIF/ VEGF axis in CLL B cells. Blood, 113, 5568-74.

Goh PP, Sze DM,Roufogalis BD (2007). Molecular and cellular regulators of cancer angiogenesis. Curr Cancer Drug Targets, 7, 743-58.

Griffiths-Jones S, Grocock RJ, van Dongen S, Bateman A, Enright AJ (2006). miRBase: microRNA sequences, targets and gene nomenclature. Nucleic Acids Res, 34, 140-4.

He Z, Chen AY, Rojanasakul Y, Rankin GO, Chen YC (2016). Gallic acid, a phenolic compound, exerts anti-angiogenic effects via the PTEN/AKT/HIF-1alpha/VEGF signaling pathway in ovarian cancer cells. Oncol Rep, 35, 291-7.

Hiroki E, Akahira J, Suzuki F, et al (2010). Changes in microRNA expression levels correlate with clinicopathological features and prognoses in endometrial serous adenocarcinomas. Cancer Sci, 101, 241-9.

Huang LE (2008). Carrot and stick: HIF-alpha engages c-Myc in hypoxic adaptation. Cell Death Differ, 15, 672-7.

Hwang HW, Mendell JT (2007). MicroRNAs in cell proliferation, cell death, and tumorigenesis. Br J Cancer, 96, 40-4.

Kuang Y, Nie YJ (2016). Exploration of the regulatory effect of $m i R-21$ on breast cancer cell line proliferation and invasion as well as the downstream target genes. Asian Pac J Trop Med, 9, 470-3.
Kung AL, Wang S, Klco JM, Kaelin WG, Livingston DM (2000). Suppression of tumor growth through disruption of hypoxia-inducible transcription. Nat Med, 6, 1335-40.

Kwak SY, Kim BY, Ahn HJ, et al (2015). Ionizing radiation-inducible miR-30e promotes glioma cell invasion through EGFR stabilization by directly targeting CBL-B. FEBS J, 282, 1512-25.

Kwon JE, Kim BY, Kwak SY, Bae IH,Han YH (2013). Ionizing radiation-inducible microRNA miR-193a-3p induces apoptosis by directly targeting Mcl-1. Apoptosis, 18, 896-909.

Landgraf P, Rusu M, Sheridan R, et al (2007). A mammalian microRNA expression atlas based on small RNA library sequencing. Cell, 129, 1401-14.

Li C, Zhao L, Chen Y, et al (2016). MicroRNA-21 promotes proliferation, migration, and invasion of colorectal cancer, and tumor growth associated with down-regulation of sec23a expression. BMC Cancer, 16, 605.

Li J, Huang H, Sun L, et al (2009). MiR-21 indicates poor prognosis in tongue squamous cell carcinomas as an apoptosis inhibitor. Clin Cancer Res, 15, 3998-4008.

Liao D, Johnson RS (2007). Hypoxia: a key regulator of angiogenesis in cancer. Cancer Metastasis Rev, 26, 281-90.

Long XH, Zhao ZQ, He XP, et al (2007). Dose-dependent expression changes of early response genes to ionizing radiation in human lymphoblastoid cells. Int $\mathrm{J} \mathrm{Mol} \mathrm{Med,}$ 19, 607-15.

Lu J, Getz G, Miska EA, et al (2005). MicroRNA expression profiles classify human cancers. Nature, 435, 834-8.

Markou A, Tsaroucha EG, Kaklamanis L, et al (2008). Prognostic value of mature microRNA-21 and microRNA-205 overexpression in non-small cell lung cancer by quantitative real-time RT-PCR. Clin Chem, 54, 1696-704.

Marta GN, Garicochea B, Carvalho AL, Real JM,Kowalski LP (2015). MicroRNAs, cancer and ionizing radiation: Where are we?. Rev Assoc Med Bras, 61, 275-81.

Melillo G (2004). HIF-1: a target for cancer, ischemia and inflammation--too good to be true?. Cell Cycle, 3, 154-5.

Motoyama K, Inoue H, Mimori K, et al (2010). Clinicopathological and prognostic significance of PDCD4 and microRNA-21 in human gastric cancer. Int J Oncol, 36, 1089-95.

Quintero M, Mackenzie N,Brennan PA (2004). Hypoxia-inducible factor 1 (HIF-1) in cancer. Eur J Surg Oncol, 30, 465-8.

Seagroves TN, Ryan HE, Lu H, et al (2001). Transcription factor HIF-1 is a necessary mediator of the pasteur effect in mammalian cells. Mol Cell Biol, 21, 3436-44.

Semenza GL (2001). Hypoxia-inducible factor 1: oxygen homeostasis and disease pathophysiology. Trends Mol Med, 7, 345-50

Simone NL, Soule BP, Ly D, et al (2009). Ionizing radiation-induced oxidative stress alters miRNA expression. PLoS One, 4, e6377.

Soucek L, Lawlor ER, Soto D, et al (2007). Mast cells are required for angiogenesis and macroscopic expansion of Myc-induced pancreatic islet tumors. Nat Med, 13, 1211-8.

Suarez Y, Sessa WC (2009). MicroRNAs as novel regulators of angiogenesis. Circ Res, 104, 442-54.

Vleugel MM, Shvarts D, van der Wall E, van Diest PJ (2006). p300 and p53 levels determine activation of HIF-1 downstream targets in invasive breast cancer. Hum Pathol, 37, 1085-92.

Volinia S, Calin GA, Liu CG, et al (2006). A microRNA expression signature of human solid tumors defines cancer gene targets. Proc Natl Acad Sci U S A, 103, 2257-61.

Wang Y, Sang A, Zhu M, et al (2016). Tissue factor induces VEGF expression via activation of the Wnt/beta-catenin 
signaling pathway in ARPE-19 cells. Mol Vis, 22, 886-97.

Xu S, Ding N, Pei H, et al (2014). MiR-21 is involved in radiation-induced bystander effects. $R N A$ Biol, 11, 1161-70.

Yan J, Liu T, Zhou X, et al (2016). FZD6, targeted by $m i R-21$, represses gastric cancer cell proliferation and migration via activating non-canonical wnt pathway. Am J Transl Res, 8 , 2354-64.

Zhang YC, Jiang G, Gao H, Liu HM, Liang J (2014). Influence of ionizing radiation on ovarian carcinoma SKOV- 3 xenografts in nude mice under hypoxic conditions. Asian Pac J Cancer Prev, 15, 2353-8.

Zhao L, Gu H, Chang J, et al (2014). MicroRNA-383 regulates the apoptosis of tumor cells through targeting Gadd45g. PLoS One, 9, e110472.

Zhou J, Brune B (2006). Cytokines and hormones in the regulation of hypoxia inducible factor-1alpha (HIF-1alpha). Cardiovasc Hematol Agents Med Chem, 4, 189-97.

This work is licensed under a Creative Commons AttributionNon Commercial 4.0 International License. 